\title{
Benefits of Hydrogen in a Segmented-Anode Plasma Torch in Suspension Plasma Spraying
}

\author{
Alice Dolmaire ${ }^{1} \cdot$ Enni Hartikainen $^{1} \cdot$ Simon Goutier $^{1} \cdot$ Emilie Béchade $^{1} \cdot$ \\ Michel Vardelle ${ }^{1} \cdot$ Pierre-Marie Geffroy $^{1} \cdot$ Aurélien Joulia $^{2}$
}

Submitted: 22 September 2020/in revised form: 6 November 2020/Accepted: 17 November 2020/Published online: 3 January 2021 (C) The Author(s) 2021

\begin{abstract}
Suspension plasma spraying (SPS) enables the production of various coating microstructures with unique mechanical and thermal properties. Aeronautical manufacturers have been working for fifty years to improve the thermal barrier coating (TBC) performances in gas turbines. Commercial plasma torches with a segmented anode that are characterized by stable plasma jets should enable a better control of the TBC microstructure. The addition of diatomic gases such as hydrogen in the plasma-forming gas affects the plasma jet formation and causes some instabilities. However, it enhances the thermal conductivity of the gas flow, the plasma mass enthalpy and the heat transfer to particles. This study aims to characterise and describe the coating microstructure changes of yttria-stabilised zirconia when gradually adding hydrogen with argon into the plasma gas mixture. The effect of hydrogen is weighted out due to the gas mass enthalpy, mean velocity at the nozzle exit and "hot zone" length of the plasma jet. The coating microstructures, which depend on these plasma jet parameters, will be mapped from feathery and porous to dense and cracked deposits depending on the spraying conditions.
\end{abstract}

Keywords columnar coatings - hydrogen microstructures · plasma jet enthalpy $\cdot$ suspension plasma spraying $\cdot$ thermal barrier coating $\cdot$ Yttria-stabilised zirconia

Alice Dolmaire

alice.dolmaire@unilim.fr

1 University of Limoges, CNRS, IRCER, UMR 7315, 87000 Limoges, France

2 Safran Tech, Rue des Jeunes Bois, 78772 Magny Les Hameaux, France

\section{Introduction}

Hydrogen is the most used diatomic gas in spraying plasma torches. It is frequently introduced as a secondary gas to enhance the net power of the torch and increase the temperature of the thermal treated material. Several papers in the literature set out theirs issues on the effect of hydrogen on "in flight" particle parameters (velocity, temperature, enthalpy) and consequently on the deposit characteristics (Ref 1-5). $\mathrm{H}_{2}$ was studied more particularly in the context of optimization of coating microstructures in air plasma spraying (APS) using "in flight" measurements such as fast pyrometers and imaging or "time of flight" velocimetry (Ref 6,7). The percentage of hydrogen in the plasma gas has been considered one of the most important parameters mastering plasma torches; the other important parameters being the arc current and primary gas flow rate. It is often used with argon but also with nitrogen (Ref 2,8$)$. Bisson et al. (Ref 9) studied the effect of hydrogen on the microstructure of TBC coatings elaborated by APS. Better deposition efficiencies (up to 75\%) and denser coatings were obtained by increasing the hydrogen flow rate. Most particles (size distribution $<40 \mu \mathrm{m}$ ) are better melted using hydrogen and more easily flatten to form a homogenous deposit with a porosity below $8 \%$. The effects of hydrogen on the standard torch working conditions are well known, i.e. increases in arc voltage (with a factor of two or three), arc voltage fluctuations and torch thermal efficiency (more than 10\%) (Ref 9-11). Indeed, the arc attachment in the anode nozzle depends on the thickness of the cold boundary layer. Few percentages of $\mathrm{H}_{2}$ are sufficient to increase the thickness of this cold zone, constrict the arc in the centre and force its attachment to move towards the nozzle exit (Ref 10,11). After a downstream movement, an upstream restrike occurs between the arc and 
the anode. The resulting voltage fluctuations are oscillating by approximately $30-70 \%$ of the mean voltage. The mean arc elongation induces an increase in voltage and global electric power, while lightly decreasing the thermal efficiency.

Recently, Mauer et al. (Ref 12) presented a paper on the role of hydrogen on the torch behaviour in low-pressure plasma spraying (LPPS). They have shown that a small percentage of hydrogen considerably changes the plasma characteristics such as electron densities, species temperatures... In air plasma spraying, phenomena are perhaps less complex because the local thermal equilibrium (LTE) is generally receivable in the jet centre at the nozzle exit, which involves the identical temperature of electrons and heavy particles $\left(T_{\text {heavy }}=T_{\mathrm{e}}\right)$. Moving away from the jet axis, the number of collisions decreases, and the temperatures of various species become different. Radially, the temperature gradients are consequently higher. Therefore, deviations from LTE may be expected in the fringes. In this zone, which approximately corresponds to $T_{\text {heavy- }}$ $<6000 \mathrm{~K}$, the thermal conductivity is relatively high due to the $\mathrm{H}_{2}$ molecule dissociation (Ref 13).

Conventional torches including a single concentric cathode and a monobloc anode have disadvantages in enabling a possibly large voltage shifting over time, high plasma fluctuations and a relatively low deposition efficiency for a fixed parameter set. The newer cascaded plasma torches, with a segmented nozzle and an anode at the end of nozzle, have the advantages of a better stability and a wide operating window (Ref 14, 15). The anode attachment area is fixed, and the fluctuations are limited. Seshadri et al. (Ref 14) compared conventional and cascaded torches and noted large differences of particle thermal and kinetic treatments. The stability is increased, and number of eddies in the periphery is widely attenuated with the cascaded torch. The saturation feed rate for zirconia powders with a wide particle size range $(-45 \mu \mathrm{m}$ $+145 \mu \mathrm{m})$ is $80 \mathrm{gpm}$ compared to $60 \mathrm{gpm}$ for a conventional F4 torch (Oerlikon, Kelsterbach, Germany). Although they are more complex and expensive, these cascaded torches are the basic tools for the future in plasma spraying (Ref 15).

The injection of very small particles (less than $1 \mu \mathrm{m}$ ) using a liquid feeding system has been involved in thermal spray for twenty years to obtain nano-structured coatings (Ref 16-18). The large fraction of interfaces is intended to provide higher hardness (small size grains), higher toughness (crack arresting effect), better wear resistance and a low thermal conductivity (Ref 18-24). The interest of the aeronautic industry is mainly growing for TBC (Thermal barrier Coatings) and EBC (Environmental Barrier Coatings). The advantage of this technic called SPS (Suspensions Plasma Spraying) is to be able to elaborate very thin layers with various microstructures: columnar, dense, homogeneous, feathery... (Ref 25-31). This microstructure depends on many parameters such as suspension load, suspension feed rate or substrate roughness (Ref 2528,30 ). Seshadri et al. (Ref 26) also recently showed that characteristics of the plasma flow, i.e., total gas flow rate and torch net power could affect coating microstructures in SPS. These characteristics can be comprehended physically as changes in fluctuations, mean mass enthalpy, mean velocity, density, viscosity or thermal conductivity of the plasma at the nozzle exit. Meanwhile studies on the treatment of suspension jet injected in a plasma generated from a conventional plasma torch (Ref 32,33 ) have shown that plasma fluctuations have a strong effect on the droplet trajectories and heterogeneity of the droplet treatment.

Fewer arc fluctuations greatly increase the homogeneity of the droplet thermal state, and hydrogen greatly changes the plasma properties as observed. This work aims to study the effect of hydrogen on SPS coating microstructures in a cascaded torch. However, we will first present the role of hydrogen in this cascaded torch on characteristics of the plasma jet: arc voltage, arc fluctuations, mass enthalpy, plasma velocity and jet length.

\section{Experimental Methods}

In this study, several technics or methods were implemented to elaborate SPS coatings of yttria-stabilised zirconia (8 mol.\% $\quad \mathrm{Y}_{2} \mathrm{O}_{3}$, IMERYS fused minerals, Laufenburg, Germany) and characterise the plasma jet mass enthalpy, mean velocity, plasma "hot zone" length and arc fluctuations.

The spraying system (Fig. 1) comprises a cascaded torch (TriplexPro-210, Oerlikon, Kelsterbach, Germany), a rotating substrate holder, a pyrometer synchronised to the presence of a moving substrate and several air jets equipped of a closed loop control. The substrates are home-made alumina button pieces $(25 \mathrm{~mm}$ in diameter; $1 \mathrm{~mm}$ in

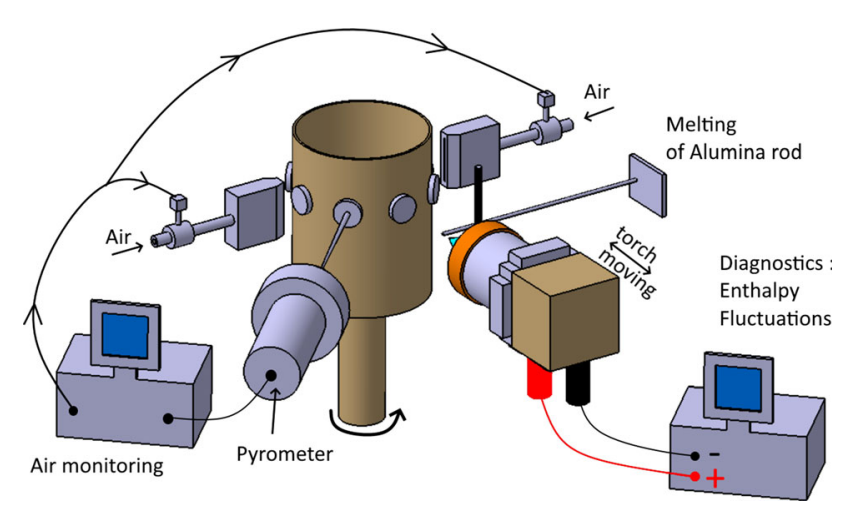

Fig. 1 Experimental set-up 
thickness). Their average roughness is $\mathrm{Ra}=3.5 \mu \mathrm{m}$ and the average maximum peak to valley height is $\mathrm{Rz}=21.6$ $\mu \mathrm{m}$. The torch and spraying parameters are presented in Table 1. In particular, injection pressure was optimized to each plasma condition (variations in the gas mixture, the total gas flow rate and arc current) using particle image velocimetry (Fig. 2) to ensure that the maximum of suspension droplets is able to penetrate the plasma and is melted from the centre of the plasma jet during spraying.

For this study, each torch parameter set will be denoted using a naming system of four numbers: the first, second, third and fourth numbers indicate the argon flow rate (slpm), helium flow rate (slpm), hydrogen flow rate (slpm) and arc current (A), as follows:

argon-helium-hydrogen-arc current

For example, a spraying condition using a gas mixture of $40 \mathrm{slpm}$ of argon and $6 \mathrm{slpm}$ of hydrogen, which operates at $480 \mathrm{~A}$, will be noted in the following diagrams as $40-0$ 6-480.

\section{Plasma Enthalpy and Velocity}

The mean mass enthalpy of the plasma $(H)$ is classically calculated from electrical parameters (arc current $I$ and arc voltage $U$ ), torch efficiency $(\eta)$ and mass flow rate $(\dot{m})$ (Ref 34) as $H=U * I * \eta / \dot{m}$.

The mean velocity of the plasma $(V)$ is roughly estimated $(\operatorname{Ref} 34,35)$ from the plasma net power $\left(P_{\text {net }}\right)$, gas isentropic ratio $\left(\gamma=C_{p} / C_{v}\right)$, nozzle section area $(A)$ and working environmental pressure $\left(p_{e}\right)$ such as $V=P_{\text {net }} *$ $\frac{(\gamma-1)}{\gamma * A * p_{e}}$, assuming a compressible and adiabatic flow in the nozzle. $\gamma$ evolves with plasma temperature (Ref 36) and decreases from 1.6 at ambient to 1.15 at approximately $13,000 \mathrm{~K}$ for a pure argon plasma. The $\gamma$ mean value was fixed at 1.25 , which is consistent with in-house velocity measurements.

\section{Plasma Jet Fluctuations and Measurement}

Plasma jet fluctuations are strongly correlated to arc voltage fluctuations. This parameter is easily measured by directly connecting wires on the torch electrodes with caution. The electrical signal is digitised at $1.7 \mathrm{MHz}$ and treated to estimate the mean voltage $\bar{U}$, voltage standard deviation $\sigma_{\mathrm{U}}$, voltage fluctuations $2 \sigma_{\mathrm{U}} / \bar{U}(\%)$ and main frequencies obtained by Fourier transform.

\section{Plasma "Hot Zone" Length (or Localisation of Alumina Rod Melting in the Plasma Jet)}

Typically, the plasma core is demarcated by isotherms $7000-8000 \mathrm{~K}$, which are very difficult to detect by any means except emission spectroscopy. However, the useful volume of the heat source, which is defined as being the zone where solid particles can heat up, is larger and can extend until the approximate isotherm $3500 \mathrm{~K}$. This value approximately matches with the temperature of a plasma flow impinging an alumina surface at its melting temperature $(2326 \mathrm{~K})$ with an overall heat transfer coefficient of $2000 \mathrm{~W} \mathrm{~m}^{-2} \mathrm{~K}^{-1}$ and a heat rate of $2 \mathrm{MW} \mathrm{m}^{-2}$ (Ref 37). The localisation of the melting tip of an alumina rod on the plasma axis enables us to estimate the "hot zone" length available for treating particles. The technique consists in slowly moving the plasma torch towards the alumina rod and noting the position when the alumina surface begins to melt. With an acceptable measuring accuracy of approximately $\pm 1 \mathrm{~mm}$, it is recognised that this parameter is major.

\section{Plasma Jet Characterisation}

Before elaborating and analysing the coatings for various parameter sets, it is fundamental to well comprehend the effects of hydrogen additions in a neutral gas plasma (Ar, $\mathrm{He})$. Except for viscosity, all plasma gas properties increase with $\mathrm{H}_{2}$ addition. At $13,000 \mathrm{~K}, 10 \mathrm{slpm}$ of $\mathrm{H}_{2}$ in a 60-slpm Ar plasma induces an enthalpy increase from $17.4 \mathrm{MJ} \mathrm{kg}^{-1}$ (set: $60-0-0-480$ ) to $21.7 \mathrm{MJ} \mathrm{kg}^{-1}$ (set: 60-0-10-480, see Fig. 5). Thermal conductivity K (Fig. 3) increases by only $0.7 \mathrm{~W} \mathrm{~m}^{-1} \mathrm{~K}^{-1}$ at $13,000 \mathrm{~K}$ between these two sets. At approximately $4000 \mathrm{~K}$, the $\mathrm{Ar}-\mathrm{H}_{2}$ mixing presents an important peak of thermal conductivity (corresponding to the $\mathrm{H}_{2}$ dissociation), which reaches the same
Table 1 Experimental parameters

\begin{tabular}{llll}
\hline \multicolumn{1}{c}{ SPS Spraying parameters } & & \multicolumn{2}{c}{ Torch parameters } \\
\hline Stand-off distance & $60 \mathrm{~mm}$ & Nozzle diameter & $9 \mathrm{~mm}$ \\
Coating surface temperature & $500{ }^{\circ} \mathrm{C}$ & Arc current & $200-500 \mathrm{~A}$ \\
Zirconia mean suspension size $\left(\mathrm{d} 50_{\mathrm{v}}\right)$ & $0.7 \mu \mathrm{m}$ & Argon flow rate & $40-100 \mathrm{slpm}$ \\
Solvent & Ethanol & Hydrogen flow rate & $0-10 \mathrm{slpm}$ \\
Suspension load & $20 \mathrm{wt} . \%$ & Helium flow rate & $0-20 \mathrm{slpm}$ \\
Injection pressure & $0.3-1.2 \mathrm{MPa}$ & & \\
\hline
\end{tabular}




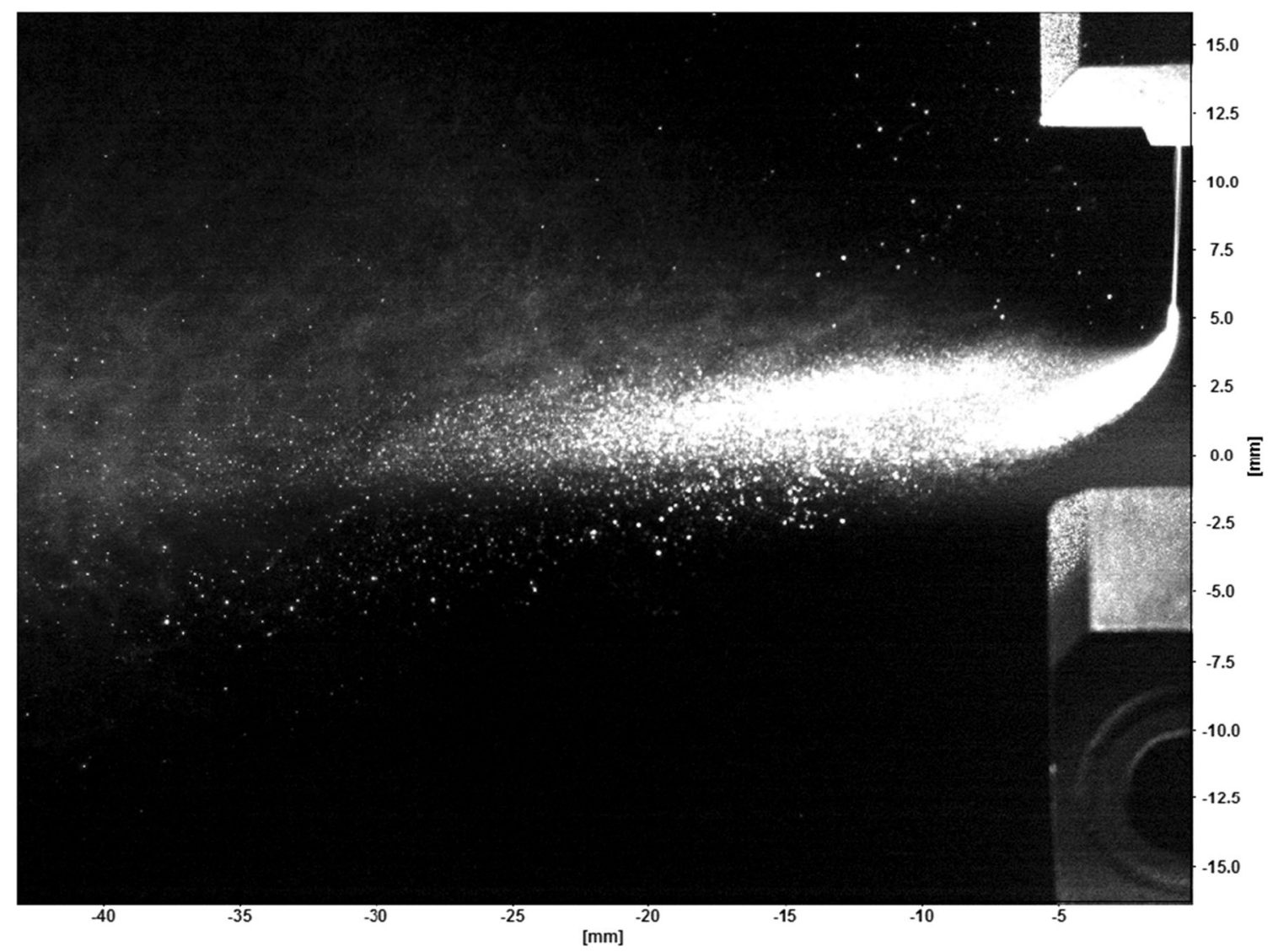

Fig. 2 Picture of suspension injection in the plasma obtained with particle image velocimetry

Fig. 3 Thermal conductivity of an argon plasma, argon

+ helium plasma and argon

$+14 \%$ hydrogen plasma (Ref

36). Parameter sets denoted by four numbers: $\mathrm{Ar}-\mathrm{He}-\mathrm{H}_{2-}$ Current (flow rate in slpm, current in A)

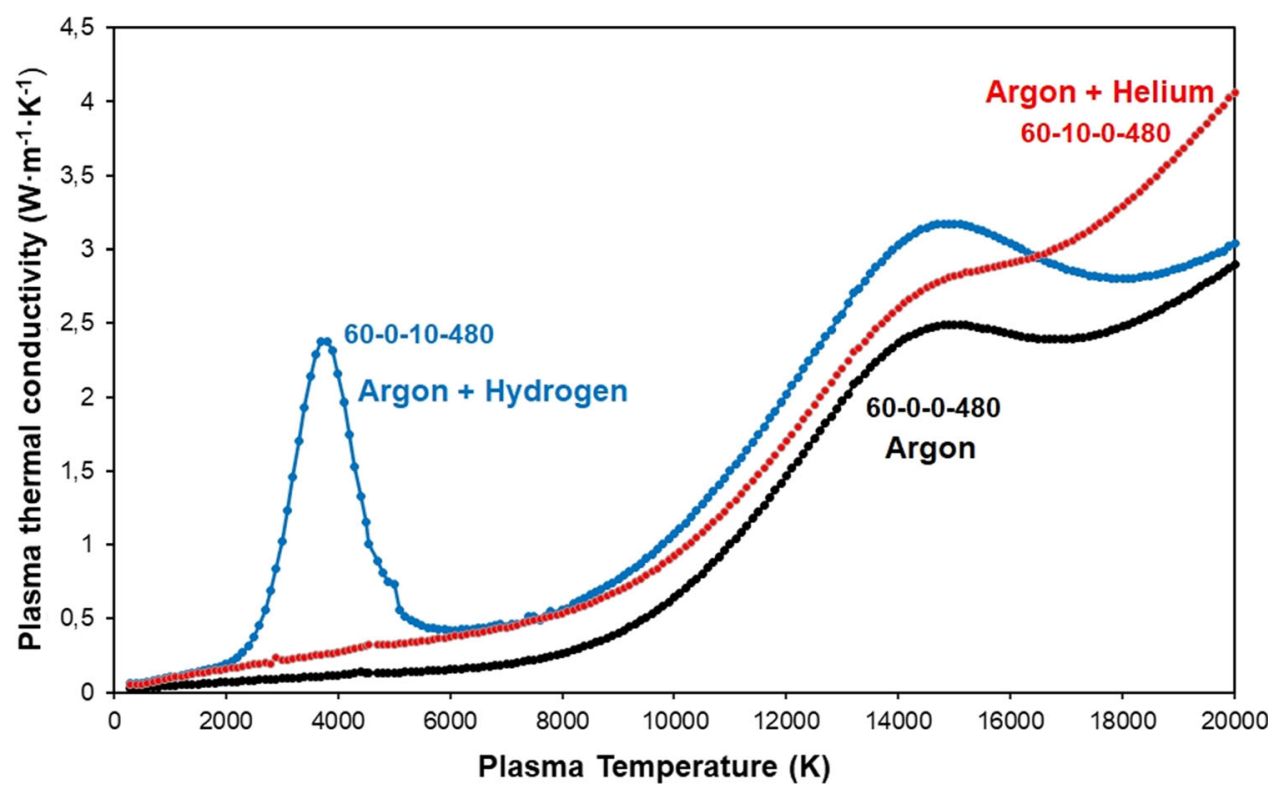

\section{Arc Voltage and Fluctuations}

Figure 4 presents a recording of the arc voltage (TriplexPro) for a plasma composed only of $60 \mathrm{slpm}$ argon (set 60-0-0-480) and a plasma with argon and 10 slpm of value as at $13,000 \mathrm{~K}\left(2.2 \mathrm{~W} \mathrm{~m}^{-1} \mathrm{~K}^{-1}\right)$. This peak of conductivity strongly affects the heat transfer to the nozzle walls and induces an increase in arc voltage (much higher for an F4 standard torch than for a segmented anode torch). 
Fig. 4 Voltage recording (TriplexPro) for the argon plasma and the argon $+14 \%$ hydrogen plasma. Parameter sets denoted by four numbers: $\mathrm{Ar}-\mathrm{He}-\mathrm{H}_{2}$-Current (flow rate in slpm, current in A)

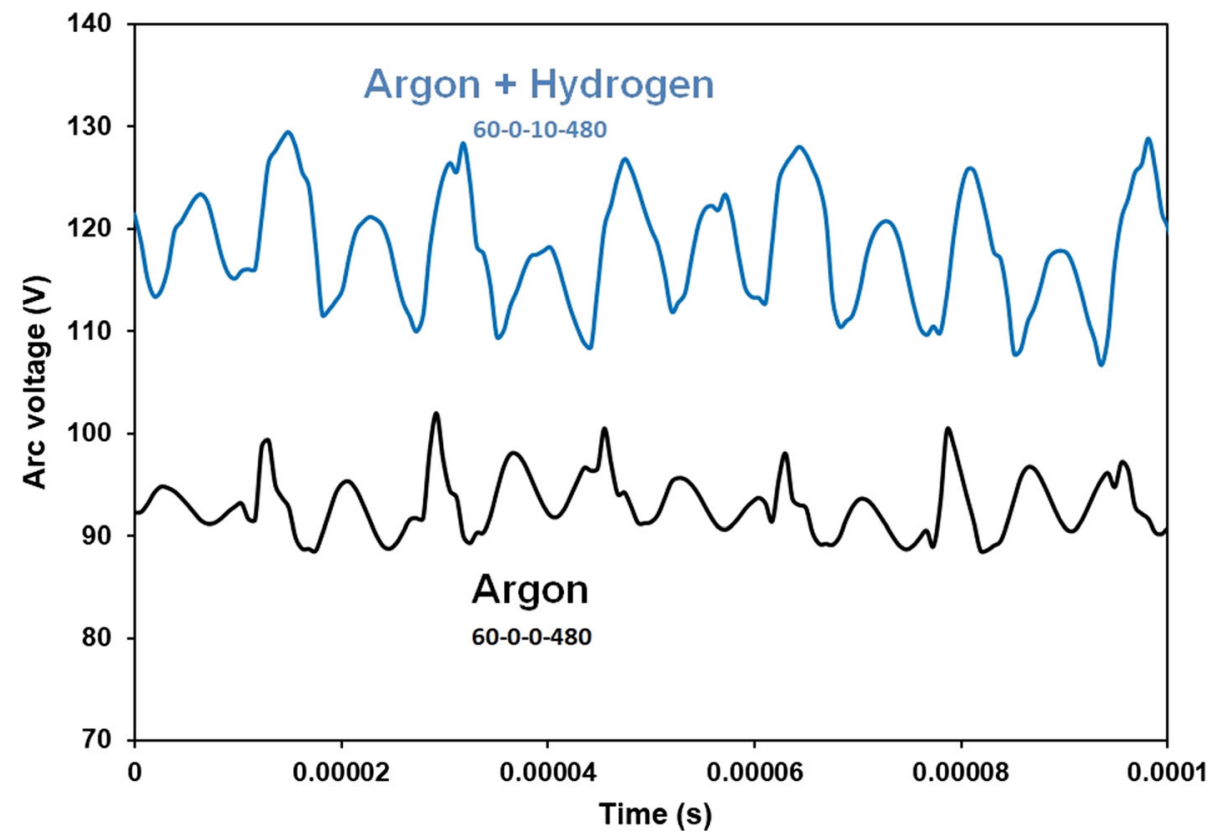

hydrogen (set: 60-0-10-480). The argon arc plasma (set 60-0-0-480) without helium and hydrogen has a mean voltage of $\bar{U}=95 \mathrm{~V}$ and a standard deviation of $\sigma_{\mathrm{U}-}$ $=2.5 \mathrm{~V}$. An addition of $10 \mathrm{slpm}$ of $\mathrm{H}_{2}$ (set: 60-0-10-480) causes a voltage of $120 \mathrm{~V}$ and a standard deviation of $\sigma_{\mathrm{U}}=6 \mathrm{~V}$. Voltage fluctuations (Fig. 6) of $2 \sigma_{\mathrm{U}} / \bar{U}$ increase from 5 to $10 \%$. In comparison with, a mono cathode and non-segmented anode (F4) and for identical plasmas sets (60-0-0-480 and 60-0-10-480), the arc voltage increases from 30 to $52 \mathrm{~V}$, and the voltage fluctuations are from 6 to $60 \%$. With this type of torch (F4), the absolute freedom of movements of the arc in the presence of $\mathrm{H}_{2}$ includes large fluctuations of voltage and subsequently high variations of the plasma volume, mainly in the flow direction. These pulsations have detrimental effects on the microstructure and quality of coatings. For a cascaded arc torch, voltage fluctuations are reduced, and the arc attachment point moves along the last stage of the segmented nozzle. At the nozzle exit, the arc can always be deformed, which increases the voltage values, but fluctuations are reduced. The measurements in Fig. 5 and 6 appear to confirm this hypothesis. Voltage uniformly increases with $\mathrm{H}_{2}$ flow rate until $125 \mathrm{~V}$ (Fig. 5), while fluctuations percentage presents a maximum (11\%) at $2 \mathrm{slpm}$ (Fig. 6), corresponding to a stabilisation of standard deviation and an increasing of mean voltage.

Similarly, the increase in argon flow rate (from 60 to $100 \mathrm{slpm}$ ) results in an increase in voltage (from 95 to $110 \mathrm{~V}$ ) due to a higher drag force on the arc. The voltage fluctuations also increase due to the arc stretching.

Moreover, when the current is increasing, the arc voltage is increasing (unlike in a F4 standard torch) due to the increase in plasma temperature, while arc fluctuations decrease due to a decrease in anode attachment zone. The increase in arc current, hydrogen and helium flow rate, are combined with an increase in mass enthalpy. In contrast, an increase in argon mass flow rate cannot balance the progression of net power despite a higher thermal efficiency and decreases the mass enthalpy (Fig. 5 and 8).

For a cascaded arc torch, the main frequency peak of the fluctuations (given by Fourier transform) is at approximately $60,000 \mathrm{~Hz}$, and another very weak peak can be noticed at approximately $2500 \mathrm{~Hz}$ independently of the gas nature. These frequencies are different from those obtained with a standard torch (F4), which are between 3000 and $6000 \mathrm{~Hz}$ and usually correspond to a "restrike mode". These fast fluctuations (every $20 \mu \mathrm{s}$ ) of the cascaded torch compared to the particle time of flight (typically approximately $1 \mathrm{~ms}$ ), are much more effective for performing a uniform heat transfer to the solid or liquid particles than for a standard torch.

\section{Plasma Jet "Hot Zone" Lengths}

As mentioned, the length of the plasma jet "hot zone" defined here approximately corresponds to an extended zone where the temperature is above $3500 \mathrm{~K}$. The range of this length greatly varies between 35 and $110 \mathrm{~mm}$ (Fig. 7) depending on the set of spraying parameters. Roughly, trends of these "hot zone" lengths versus mass enthalpy are identical to those for voltages versus mass enthalpy, except for argon. Since the argon flow rate is increasing, plasma "hot zone" lengths appear to be stabilising at approximately $75 \mathrm{~mm}$. This increase in flow rate is 
Fig. 5 Arc voltage for various parameter sets denoted by 4 numbers: Ar-He- $\mathrm{H}_{2}$-Current (flow rate in slpm, current in A, accuracy: $\pm 1 \mathrm{~V}$ )

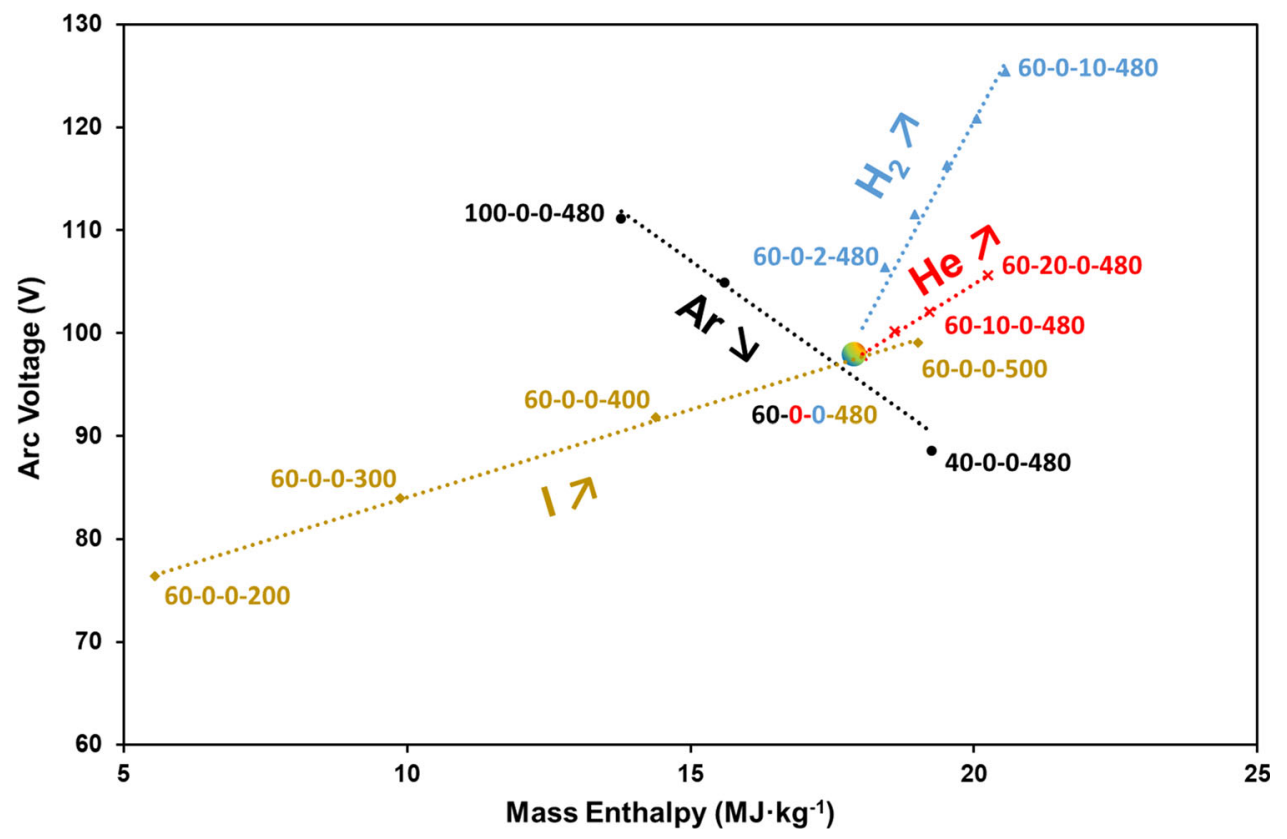

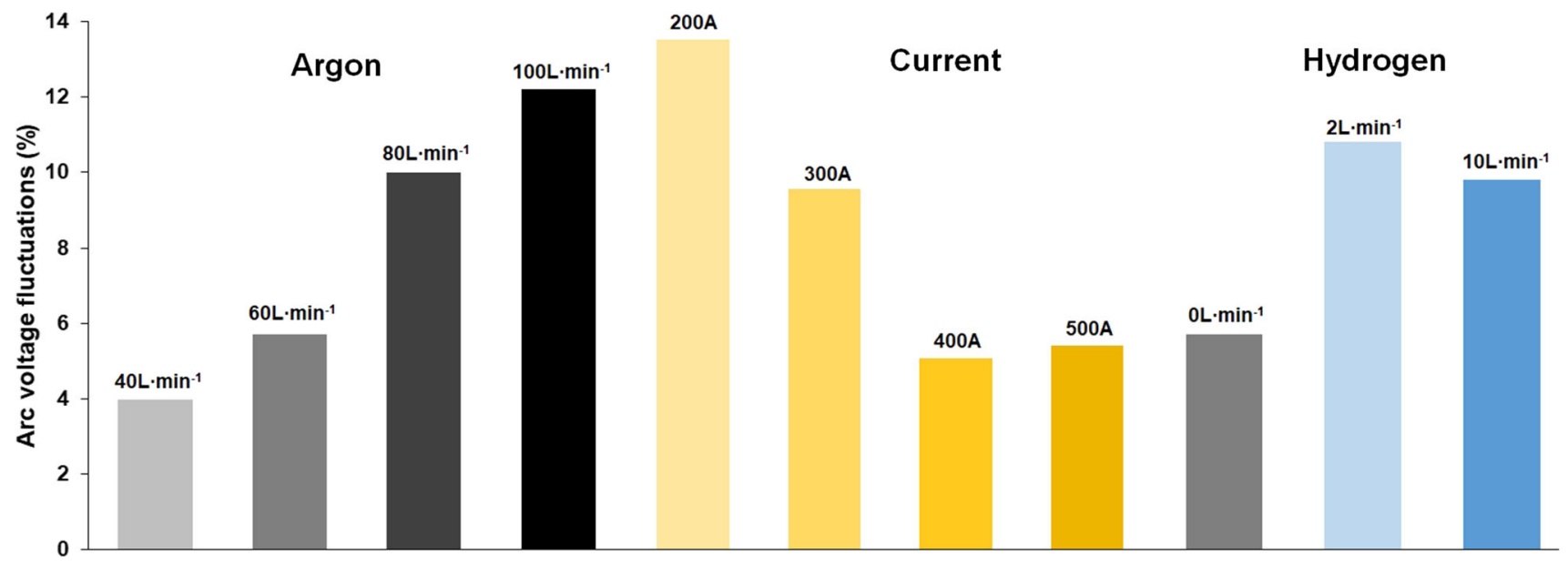

Fig. 6 Arc voltage fluctuations $\left(2 \sigma_{\mathrm{U}} / \bar{U}\right)$ depending on the flow rates (slpm) or current (A)

accompanied by an increase in plasma velocity, which produces a magnified effect of turbulence. Therefore, a lot of air is pumped, and the end of the jet cools down faster. Amongst the secondary gases, the addition of 20 slpm in helium only results in a jet length below $80 \mathrm{~mm}$, whereas hydrogen has an important effect on the "hot zone" length extension. The value of $110 \mathrm{~mm}$ is reached by adding 10 slpm of hydrogen due to the increase in enthalpy and thermal conductivity with a high peak at approximately $4000 \mathrm{~K}$, as previously shown.

To complete this analysis of plasma characteristics, the plasma velocities can be calculated. A map of mass enthalpy versus plasma velocity (Fig. 8) is drawn for the standard parameter ranges: the current is $300-500 \mathrm{~A}$, the argon flow rate is $40-100 \mathrm{slpm}$, the hydrogen flow rate is
$0-10$ slpm, and the helium flow rate is $0-20$ slpm. We note that:

- The arc current is the main parameter that enables an increase in mass enthalpy and mean velocity (see the 60-0-0-300 to 60-0-0-480 sets)

- Inversely, the increase in argon flow rate from 40 to $100 \mathrm{slpm}$ makes the velocity increase by $500 \mathrm{~ms}^{-1}$ and the mass enthalpies decrease by $6 \mathrm{MJ} \mathrm{kg}^{-1}$.

- For a given argon flow rate, an increase in hydrogen flow rate induces an increase in enthalpy and velocity aligned with the evolution of enthalpy and velocity with the arc current (e.g. sets 60-0-0-480 and 60-0-10-480)

- An argon plasma with 20 slpm of helium has approximately identical characteristics (enthalpy-velocity) to an argon plasma with $10 \mathrm{slpm}$ of $\mathrm{H}_{2}$. 
Fig. 7 Hot zone lengths defined at $\mathrm{T}\left(\mathrm{Al}_{2} \mathrm{O}_{3}\right)_{\text {melt }}(\mathrm{mm})$.

Parameter sets denoted by four numbers $\mathrm{Ar}-\mathrm{He}-\mathrm{H}_{2}-\mathrm{Current}$ (flow rate in slpm, current in $\mathrm{A}$, accuracy: $\pm 1 \mathrm{~mm}$ )

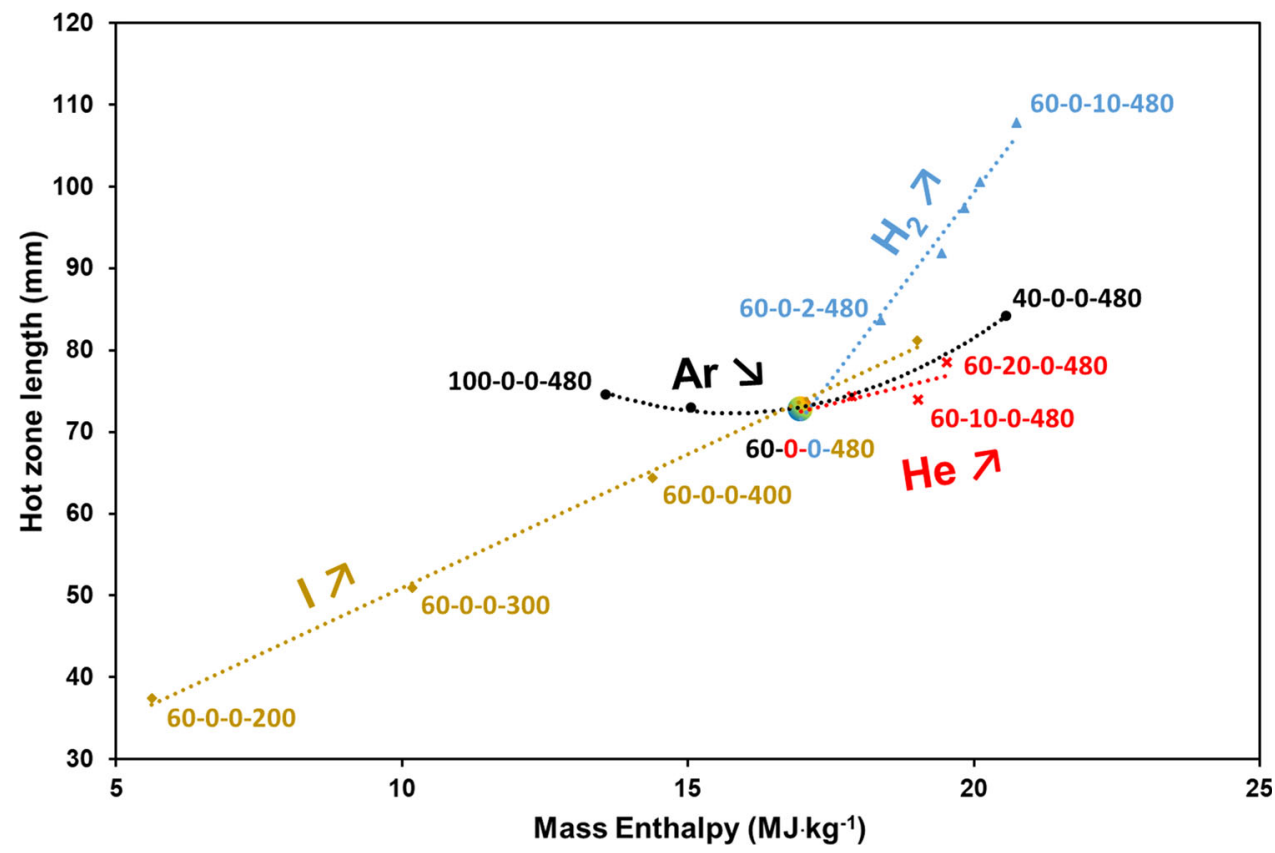

- 10 slpm of hydrogen induces up to $5 \mathrm{MJ} \mathrm{kg}^{-1}$ more to the mass enthalpy of an argon plasma

- The combination of the three plasma gases $\left(\mathrm{Ar}-\mathrm{He}-\mathrm{H}_{2}\right)$ enables the plasma jet enthalpy to reach values above $26 \mathrm{MJ} \mathrm{kg}^{-1}$.

To conclude, this cascaded arc torch has a very large working range. It is much more stable than a classical torch with a one-piece nozzle, and its fluctuations main frequency is very high. Hydrogen considerably improves the range of plasma jet mass enthalpy and velocity while maintaining a weak level of fluctuations and drastically increasing the plasma jet "hot zone" length.

\section{Coating Microstructures}

This subsection aims to answer the following question: Are plasma jet mass enthalpy and mean velocity sufficient to describe a plasma jet and explain the associated coating microstructure?
Fig. 8 Plasma enthalpy/ velocity mapping, parameter sets denoted by four numbers: $\mathrm{Ar}-\mathrm{He}-\mathrm{H}_{2}$-Current (flow rate in slpm, current in A)

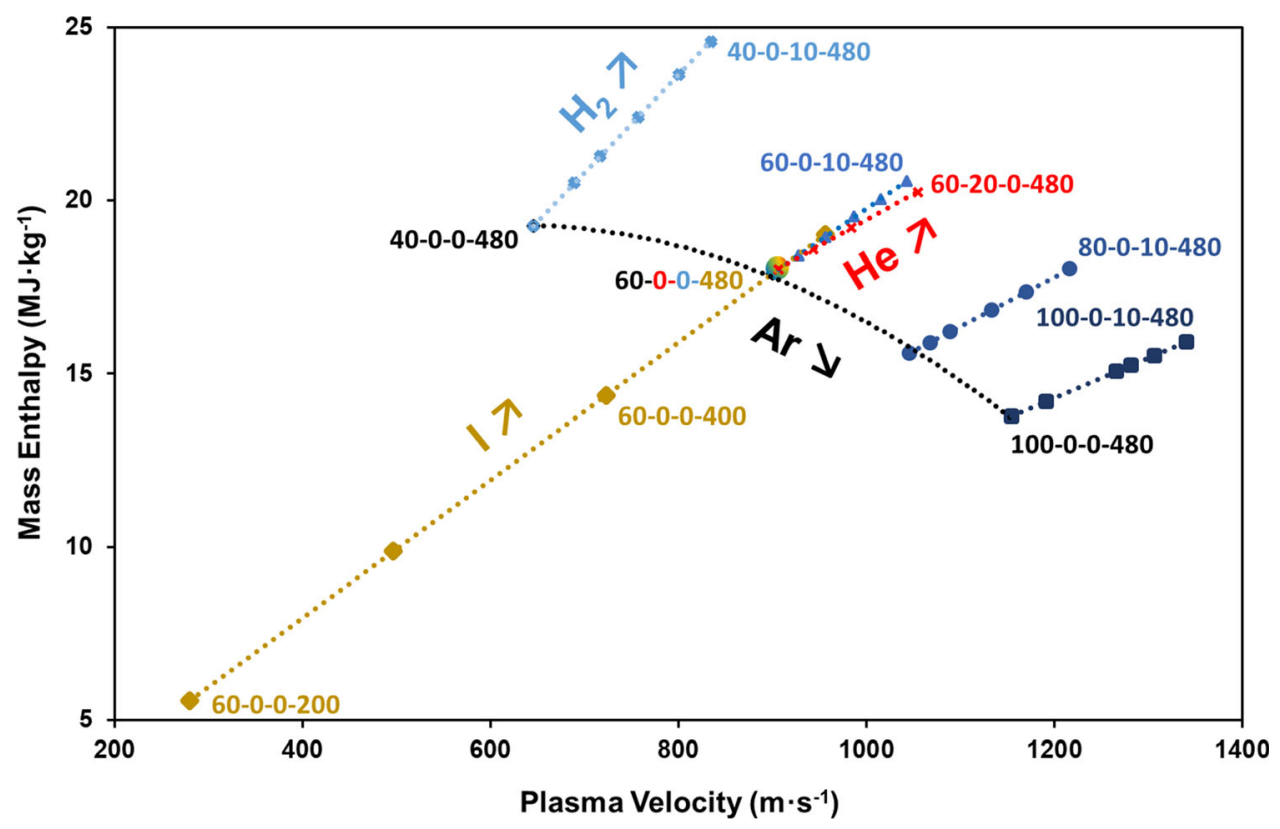




\section{Coating Microstructures of Different Plasma Compositions with Identical Plasma Jet Mass Enthalpy and Velocity Values}

Two coatings were sprayed and compared using a couple of parameter sets (60-10-2-480 denoted by A and 60-0-8480 denoted by B) with approximately identical plasma mass enthalpy $\left(20 \mathrm{MJ} \mathrm{kg}^{-1}\right)$ and velocity $\left(1020 \mathrm{~ms}^{-1}\right)$, but different gas mixture compositions (see mapping of Fig. 17). The first set (A) is comprised of secondary gases of $10 \mathrm{slpm}$ of helium and 2 slpm of hydrogen, while the second set (B) without hydrogen has 8 slpm of hydrogen to compensate the lack of enthalpy and velocity with respect to set A. Coating cross sections are presented in Fig. 9. For comparison, a bar chart graph provides the variation (in percentage) of plasma properties between the two sets, such as plasma mass enthalpy, temperature, velocity, fluctuations, "hot zone" length, column width and micrometric total porosity of the resulting columnar coatings.

We note:

- A microstructure with rather conical and irregular columns in both coatings.

- Some columns don't seem to start from the interface with the substrate in both coatings.

- An increase in column width (+20\%) confirms a better densification with the addition of hydrogen.

- Higher porosity (11.5 vol.\%) inside columns for set A than set B (8 vol.\%).

These microstructures look similar with a better densification for set B (-30\% in porosity). The largest amount of hydrogen for set B $(\sim 12 \%$ of the total gas flow rate, compared to $3 \%$ in set A) with a higher thermal conductivity at $4000 \mathrm{~K}$ causes an increase in plasma "hot zone" length $(+13 \%)$ and a longer time of flight in the "hot zone". A better heat transfer is surely responsible of the changing microstructure.

In conclusion, the plasma jet mass enthalpy and velocity are not sufficient to explain a specific microstructure. The plasma composition (particularly the presence of hydrogen) affects the coating microstructure and compositions.

\section{Evolution of the Coating Microstructure with Increasing Arc Current}

This section aims to study the effect of the arc current on the coating microstructure. Plasma properties and coating microstructures of set 60-0-6-300 denoted by $\mathrm{C}$ and set 60-0-6-500 denoted by D (see mapping of Fig. 17) are compared below.

The increase in arc current from 300 to $500 \mathrm{~A}$ has a beneficial effect on the column compactness $(-8 \%$ in porosity) and column width $(+57 \%)$. The column width (Fig. 10) is increasingly broader (from 37 to $68 \mu \mathrm{m}$ ) with increasing arc currents (from 300 to $500 \mathrm{~A}$ ). This trend is closely linked to the increase in plasma mass enthalpy and mean velocity $(+70 \%)$, which causes an increase in particle temperatures and velocities, a better flattening on the substrate and a better compactness. It is also combined with a small decrease in fluctuations, and much more interestingly, an increase in "hot zone" length $(+29 \%)$. Therefore, the particle heat treatment is of better quality within the plasma jet. All evolutions of plasma properties are positive for a better thermal and kinetic treatment of particles. Furthermore, this increase in plasma jet velocity enables a higher axial component of the particle velocity, which results in a weaker particle divergence. This weak divergence decreases the flux of particles travelling parallel
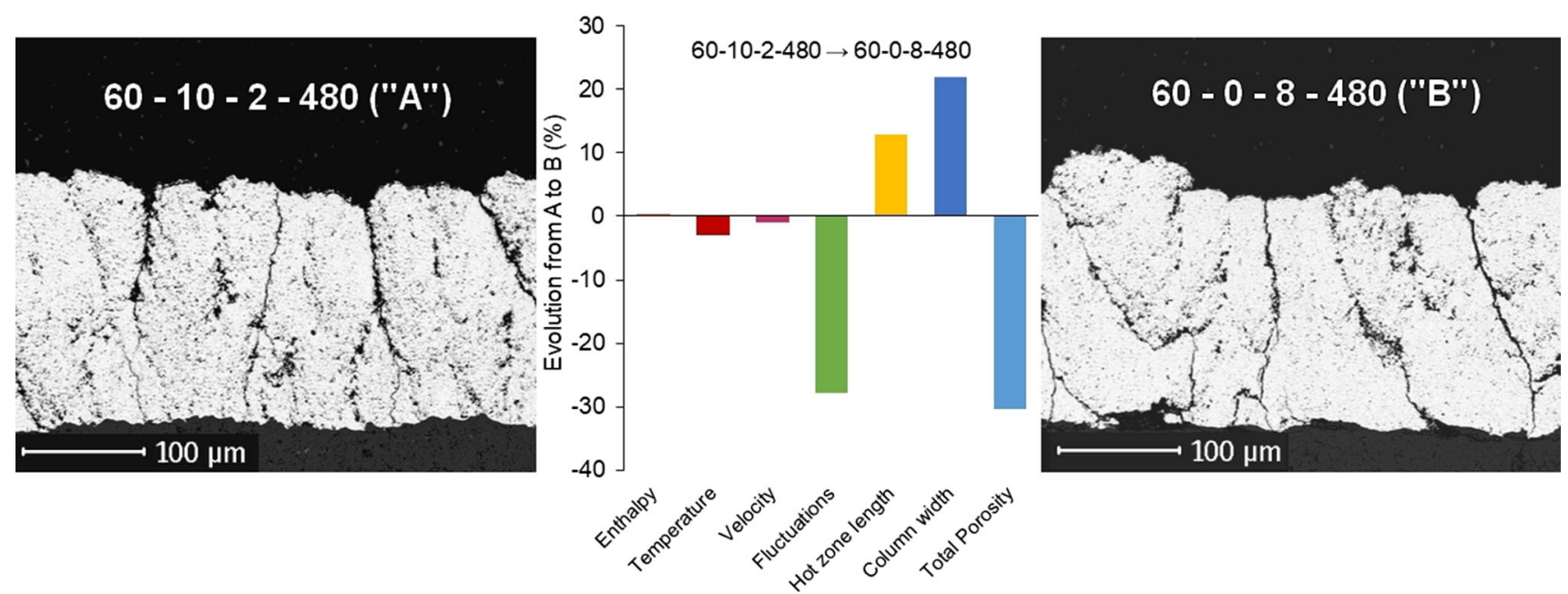

Fig. 9 Coating cross sections for 2 sets (A and B) with different gas mixture compositions, but identical plasma enthalpy and velocity. Evolution of plasma and coating properties (in \%) when set A evolves to set B 

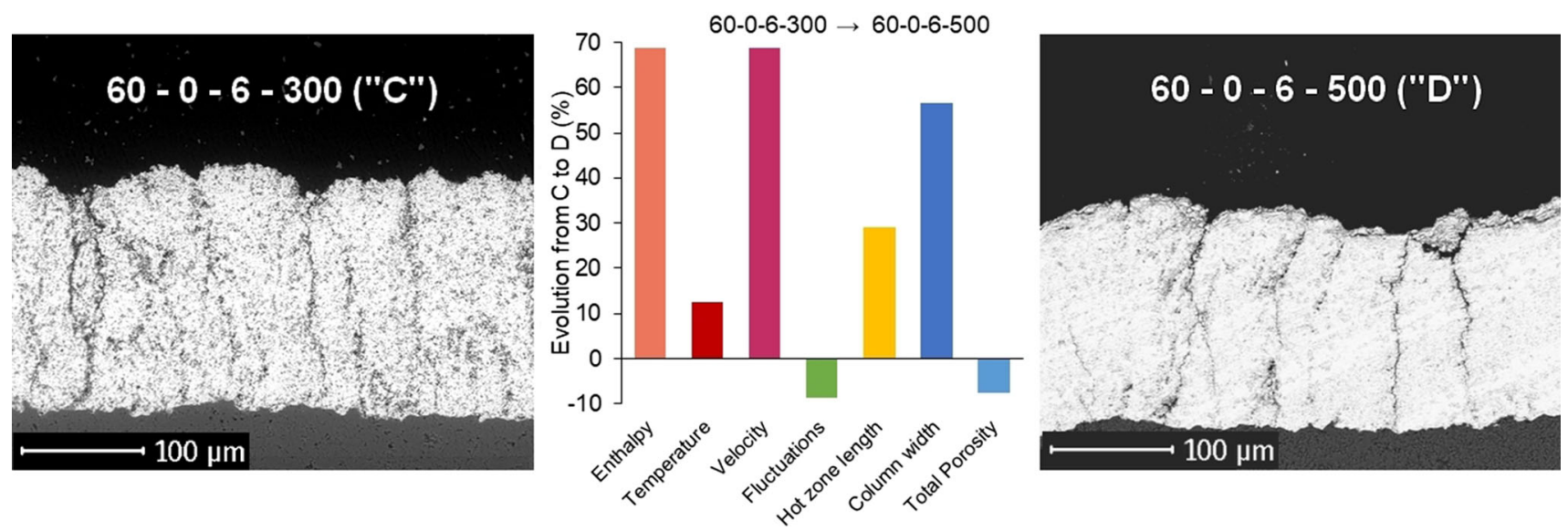

Fig. 10 Coating cross sections corresponding to a current increase (from 300 to 500 A). Evolution of the plasma and coating properties (in \%) when set $C$ evolves to set $D$

Table 2 Torch parameter sets (Ar-He- $\mathrm{H}_{2}$-current) for specific points represented Fig. 16

\begin{tabular}{lccc}
\hline Point & Torch parameter sets & Point & Torch parameter sets \\
\hline A & $60-10-2-480$ & G & $60-10-0-480$ \\
B & $60-0-8-480$ & H & $60-10-10-480$ \\
C & $60-0-6-300$ & I & $80-10-0-480$ \\
D & $60-0-6-500$ & J & $80-10-10-480$ \\
E & $40-10-0-480$ & K & $100-0-0-400$ \\
F & $40-10-10-480$ & L & $100-0-8-400$ \\
\hline
\end{tabular}

to the substrate and mitigates the "shadow" effect. Hence, a decrease in column concentration and an increase in their wideness are noted.

To continue this study, four set couples (Table 2) corresponding to an addition of hydrogen (sets $\mathrm{E}$ and $\mathrm{F}, \mathrm{G}$ and $\mathrm{H}$, I and $\mathrm{J}$, and $\mathrm{K}$ and $\mathrm{L}$ ) and the associated coating microstructures were compared.

These four couples correspond to four argon flow rates: 40 (points $\mathrm{E}$ and $\mathrm{F}$ ), 60 ( $\mathrm{G}$ and $\mathrm{H}$ ), 80 (I and $\mathrm{J}$ ), and 100 slpm ( $\mathrm{K}$ and $\mathrm{L}$ ).

Does the addition of hydrogen always have a beneficial impact on the coating microstructure? The coating microstructures in connection with associated plasma properties will be closely examined in the following sections to answer this last question.

\section{Effect of the Hydrogen Flow Rate on SPS Coating Microstructures}

Coating Microstructures for Sets Including 40 slpm of Ar and 0 or 10 slpm of $\mathrm{H}_{2}$

The coating cross sections and bar chart graph are presented in Fig. 11 (set 40-10-0-480 denoted by $\mathrm{E}$ and set 40-10-10-480 denoted by F). Set F plasma gas has $20 \%$ of hydrogen compared to set E without hydrogen. Such important percentage of $\mathrm{H}_{2}$ usually greatly changes the plasma properties. From set $\mathrm{E}$ to set $\mathrm{F}$, the voltage increases from 94 to $123 \mathrm{~V}$, and the mass enthalpy increases from 22.8 to $27 \mathrm{MJ} \mathrm{kg}^{-1}$.

From set $\mathrm{E}$ to set $\mathrm{F}$, the coating porosity decreases with hydrogen increase due to the increase in the "hot zone" length $(+62 \%)$. Columns are broader $(+20 \%)$, and the crack width is smaller due to a better thermal treatment (high increase in hot zone length) and kinetic treatment $(+19 \%$ in velocity). The sharp increase in fluctuations $(+166 \%)$ do not appear to affect the microstructure, due to the very high frequencies $(60 \mathrm{kHz})$ of arc fluctuations. Moreover, as previously mentioned, arc fluctuations for a cascaded arc torch do not affect the heat and kinetic treatment of particles.

The addition of hydrogen boosts the coating compactness at the cost of a small increase in column width.

Coating microstructure for sets with 60 slpm of Ar and 0 or 10 slpm of $\mathrm{H}_{2}$

The coating cross sections and bar chart graph are presented in Fig. 12 (set 60-10-0-480 denoted by G and set 60-10-10-480 denoted by $\mathrm{H}$ ). The conditions are identical for the previous couple of sets but with $60 \mathrm{slpm}$ of argon.

- Set $\mathrm{G}$ has a more irregular and porous microstructure than for set E with 40 slpm of argon. With respect to set $E$, the mass enthalpy of set $G$ plasma jet is reduced (from 22.8 to $19 \mathrm{MJ} \mathrm{kg}^{-1}$ ), and its velocity is increased (from 790 to $970 \mathrm{~ms}^{-1}$ ). For a roughly similar "hot zone" length $(\sim 75 \mathrm{~mm})$ and a higher velocity, the time of flight of set $G$ particles and time for heat treatment decrease, so the columns can be more porous.

- The trends between set $\mathrm{G}$ and set $\mathrm{H}$ are identical to the transition between set $\mathrm{E}$ and set $\mathrm{F}$ : as a whole, the 

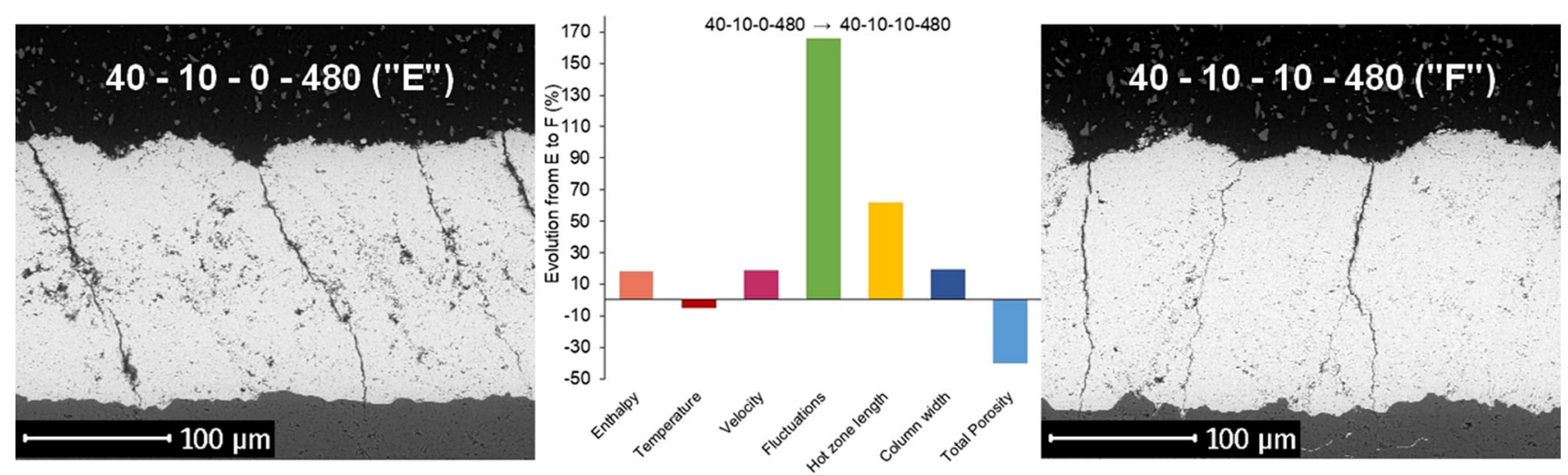

Fig. 11 Plasma parameters and coating changes when set $\mathrm{E}$ evolves to set $\mathrm{F}$
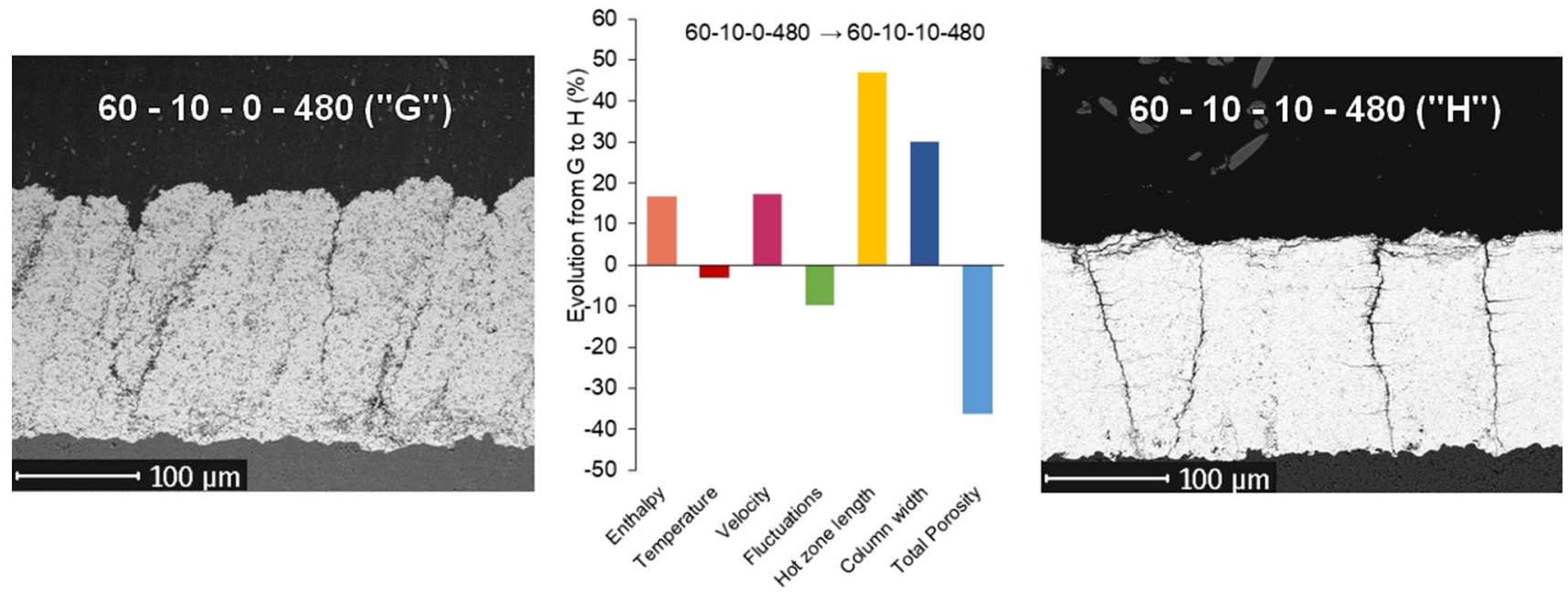

Fig. 12 Plasma parameters and coating changes when set $\mathrm{G}$ evolves to set $\mathrm{H}$

coating microstructure is denser, but some small cracks parallel to the substrate are observed along vertical cracks, particularly in the higher part of the deposit. Due to stress relaxations, these cracks can be linked to the temperature gradient during the process and/or during the cooling of the deposit.

- The column widths for set $\mathrm{H}$ and set $\mathrm{F}$ are identical (approximately $66 \mu \mathrm{m}$ ), which confirms the identical compactness

The effect of hydrogen addition is the same in an argon plasma with flow rates between 40 and 60 slpm. Specifically, it leads to a lesser porosity and a higher column width.

Because the trends for 80 slpm of argon (sets I and J) are exactly identical, a detailed description of the microstructures is not provided to simplify this presentation.
Coating Microstructure for Sets with 100 slpm of Argon and 0 or 8 slpm of $\mathrm{H}_{2}$

The last couple of sets (set 100-0-0-400 noted $\mathrm{K}$ and set 100-0-8-400 noted L) has identical variations to the previous couples. However, the arc current decreased at $400 \mathrm{~A}$ to maintain the plasma jet velocity range at approximately $1000 \mathrm{~ms}^{-1}$. The "hot zone" length for set $\mathrm{K}$ is approximately $75 \mathrm{~mm}$ for all sets with high flow rates. Indeed, the increase in argon flow rate induces a higher air pumping and jet cooling.

In Fig. 13, the coating microstructure obtained from set $\mathrm{K}$ (without hydrogen) is porous with conical columns as expected. The coating microstructure obtained from set $\mathrm{L}$ with 8 slpm of hydrogen has narrow and parallel columns (41 $\mu \mathrm{m}$ in width), which is required for TBC.

Globally, the introduction of 8 or $10 \mathrm{slpm}$ of hydrogen in a high flow rate of argon is very efficient to obtain a 

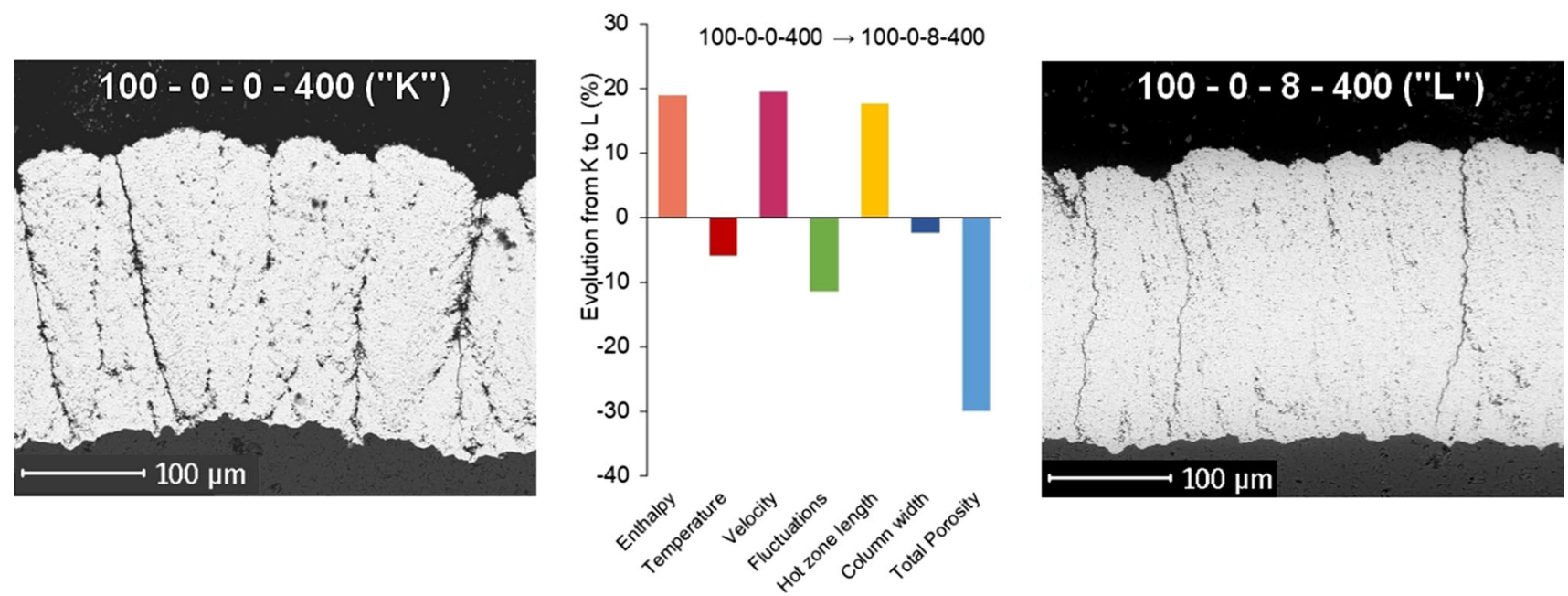

Fig. 13 Plasma parameters and coating changes when set $\mathrm{K}$ evolves to set $\mathrm{L}$

Fig. 14 Hot zone length defined at $\mathrm{T}\left(\mathrm{Al}_{2} \mathrm{O}_{3}\right)_{\text {melt }}$ for various parameter sets

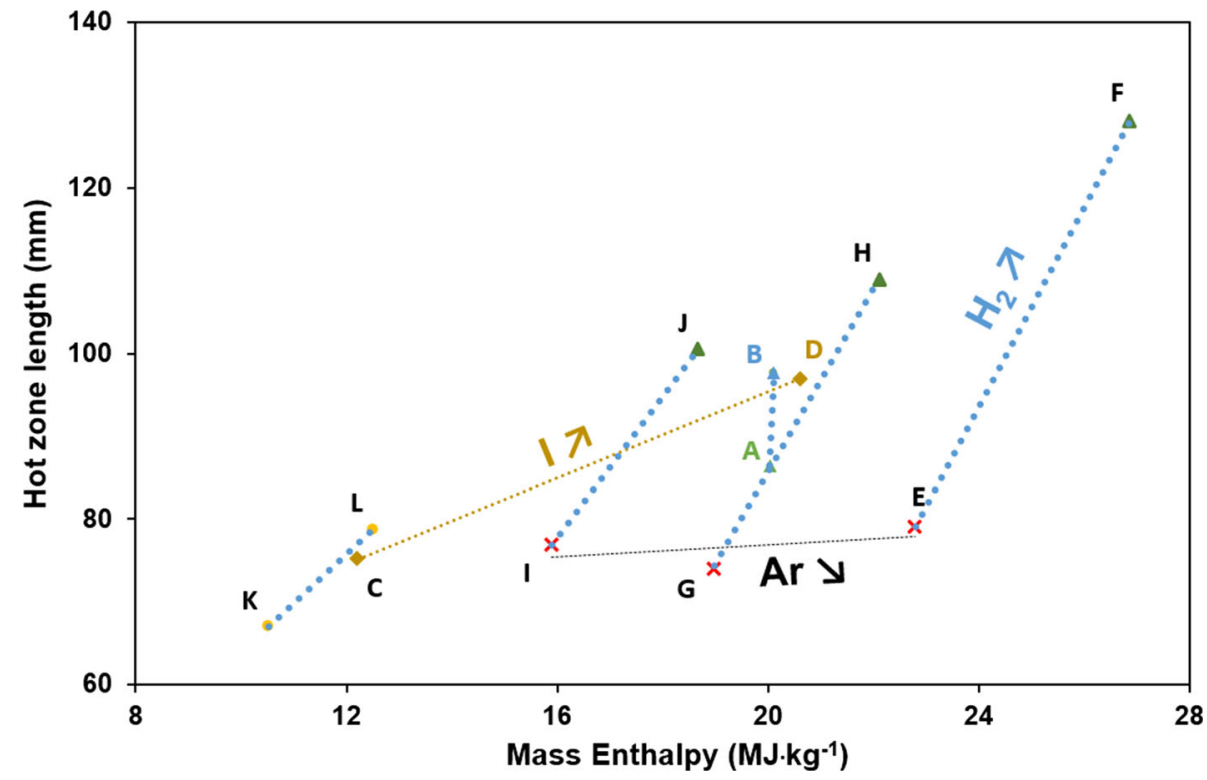

better compactness and an identical column width. A higher argon flow rate corresponds to more parallel and regular columns.

\section{Synthesis}

To obtain a global view of the results, the plasma "hot zone" lengths and coating parameters such as the total porosity and column width are presented in Fig. 14, Fig. 15 and Fig. 16. The plasma gas mixtures of sets E, G, I and K do not contain hydrogen.

The main trends are:

- Hot zone" lengths (Fig. 14) are greatly affected by the presence of $\mathrm{H}_{2}$ due to the thermal conductivity peak at
$4000 \mathrm{~K}$. Without hydrogen in the plasma gas, the "hot zone" lengths are reduced in the range of 70-80 $\mathrm{mm}$. With hydrogen, the plasma "hot zone" lengths are always increasing, up to $130 \mathrm{~mm}$, and the increase is much more effective for small flow rates of argon $(+62 \%$ for set $\mathrm{F})$ than for high flow rates $(+18 \%$ for set $\mathrm{L}$ ). The $\mathrm{H}_{2}$ percentage is the most influent parameter on the plasma jet "hot zone" lengths (followed by the arc current).

- The column width (Fig. 15) is globally increasing with plasma mass enthalpy. It is doubled between enthalpies of 12 and $25 \mathrm{MJ} \mathrm{kg}^{-1}$, which correspond to argon flow rates evolving from 100 to $40 \mathrm{slpm}$. Moreover, the column width increases by $50 \%$ with the addition of $\mathrm{H}_{2}$ and with the increase in arc current. The particle temperature increases with mass enthalpy, while the 
Fig. 15 Column width for the studied parameter sets
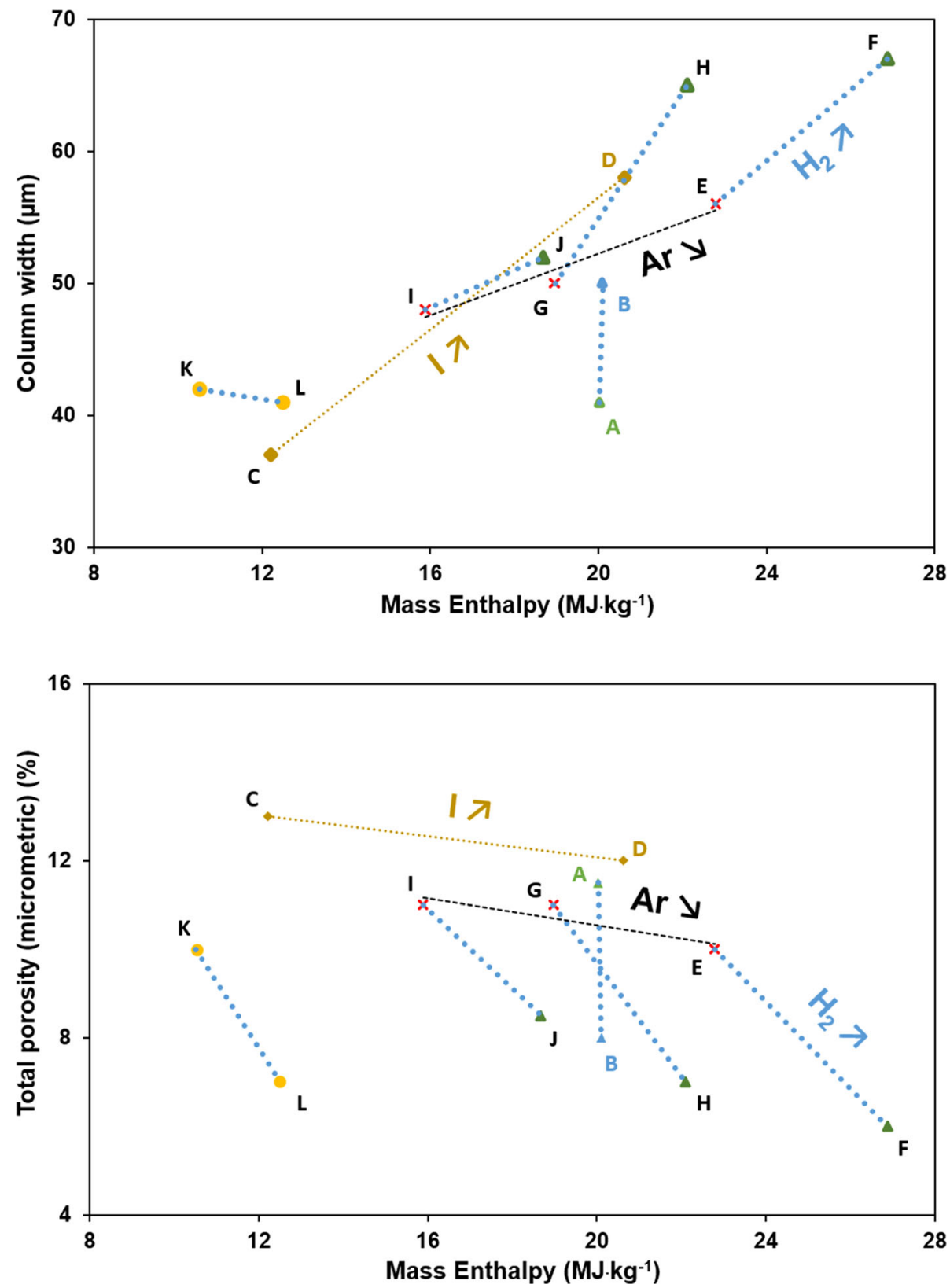

compactness is improved and the crack number is reduced.

- Columnar microstructure evolves a lot with $\mathrm{H}_{2}$ presence in plasma gas: total porosity (Fig. 16) is decreasing of $30 \%$ with addition of 10 slpm of $\mathrm{H}_{2}$. Finally, contrary to what one may think, the increase in argon flow rate does not significantly decrease total porosity (see sets F, H, J, L).

The coating cross sections are compiled in Fig. 17. This mapping shows global trends on the effect of the plasma jet mass enthalpy and mean velocity on yttria-stabilised zirconia coating microstructures:
- Mass enthalpy tends to shape the column morphology. Below $15 \mathrm{MJ} \mathrm{kg}^{-1}$, independently of the plasma jet velocity or percentage of $\mathrm{H}_{2}$ in the gas mixture, narrow and parallel columns are obtained. Above a threshold in mass enthalpy of $23 \mathrm{MJ} \mathrm{kg}^{-1}$, broad columns of zirconia are obtained independently of the plasma jet velocity. Dense and broad columns are obtained when high-plasma jet mass enthalpies are combined with the highest extension of plasma "hot zone" lengths (more than $100 \mathrm{~mm}$ ), due to the addition of $\mathrm{H}_{2}$ at low Ar flow rates $(40-60 \mathrm{slpm})$. The times of flight of particles in "hot zones" are significantly improved in these cases. 
Fig. 17 Coating

microstructures in a plasma mass enthalpy-mean velocity mapping

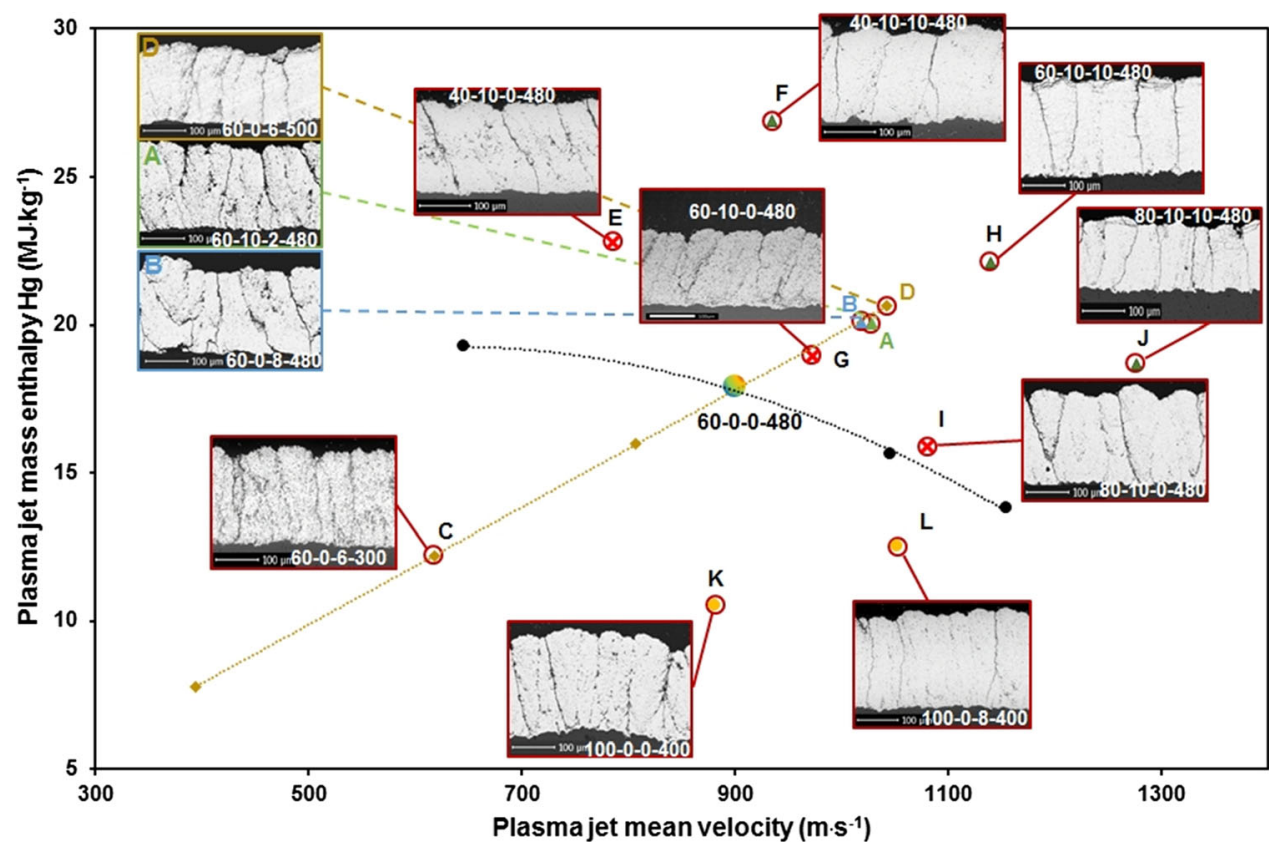

- For a set value of enthalpy, an increase in plasma jet mean velocity causes the compaction and densification of the columns.

- As previously shown, the addition of $\mathrm{H}_{2}$ in the gas mixture causes broader and denser columns when we compare coatings from plasma jets of identical mass enthalpy and mean velocity.

\section{Conclusions}

The main conclusions are:

- With hydrogen, the arc fluctuations $\left(2 \sigma_{\mathrm{U}} / \bar{U}\right)$ remain below $15 \%$, and the high frequencies of approximately $60 \mathrm{kHz}$ do not affect or barely affect the heat and kinetic treatment.

- The fluctuation increase (up to $15 \%$ ) with $\mathrm{H}_{2}$ does not affect the coating microstructures of $8 \mathrm{~mol} \%$ yttriastabilised zirconia.

- The addition of $10 \mathrm{slpm}$ of $\mathrm{H}_{2}$ in the total gas flow rate on average results in a $+15 \%$ increase in mass enthalpy and $+20 \%$ increase in plasma velocity.

- The columnar microstructure greatly evolves with the addition of $\mathrm{H}_{2}$ in the plasma gas mixture: column compactness and parallelism are greatly improved.

- The column widths mainly depend on the plasma "hot zone" lengths and consequently on the percentage of $\mathrm{H}_{2}$ in the plasma gas mixture.

- The plasma jet mass enthalpy drives the columnar morphology; below the threshold value of $15 \mathrm{MJ} \mathrm{kg}^{-1}$, narrow and parallel columns are obtained, above the threshold value of $23 \mathrm{MJ} \mathrm{kg}^{-1}$, broad columns can be attained.

- The plasma jet mean velocity helps in making dense and compact columns for a set value of mass enthalpy.

- An increase in $\mathrm{H}_{2}$ percentage in the plasma gas mixture causes denser and broader columns of yttria-stabilised zirconia when we compare the coatings obtained with plasma jets that exhibit identical mass enthalpy and mean velocity values.

In conclusion, the benefits of hydrogen in a segmentedanode plasma torch for SPS are straightforward. Its addition to the plasma gas mixture provides a better melting of particles without disadvantages associated with arc fluctuations as in a standard torch and helps to elaborate denser columnar coatings (column width $<80 \mu \mathrm{m}$ ).

Open Access This article is licensed under a Creative Commons Attribution 4.0 International License, which permits use, sharing, adaptation, distribution and reproduction in any medium or format, as long as you give appropriate credit to the original author(s) and the source, provide a link to the Creative Commons licence, and indicate if changes were made. The images or other third party material in this article are included in the article's Creative Commons licence, unless indicated otherwise in a credit line to the material. If material is not included in the article's Creative Commons licence and your intended use is not permitted by statutory regulation or exceeds the permitted use, you will need to obtain permission directly from the copyright holder. To view a copy of this licence, visit http://creativecommons. org/licenses/by/4.0/.

\section{References}

1. M. Friis, C. Persson, P. Nylen, and J. Wigren, Investigation of Particle In-flight Characteristics During Atmospheric Plasma 
Spraying of Yttria-Stabilized $\mathrm{ZrO}_{2}$ : Part 1. Experimental, $J$. Therm. Spray Technol., 2001, 10(2), p 301-310

2. B.R. Marple, R.S. Lima, C. Moreau, S.E. Kruger, L. Xie, and M.R. Dorfman, Yttria-Stabilized Zirconia Thermal Barriers Sprayed Using $\mathrm{N}_{2}-\mathrm{H}_{2}$ and Ar- $\mathrm{H}_{2}$ Plasmas: Influence of Processing and Heat Treatment on Coating Properties, J. Therm. Spray Technol., 2007, 16(5-6), p 791-797

3. Y.P. Wan, V. Gupta, Q. Deng, S. Sampath, V. Prasad, R. Williamson, and J.R. Fincke, Modeling and Visualization of Plasma Spraying of Functionally Graded Materials and Its Application to the Optimization of Spray Conditions, J. Therm. Spray Technol., 2001, 10(2), p 382-389

4. M. Vardelle, A. Vardelle, and P. Fauchais, Spray Parameters and Particle Behavior Relationships During Plasma Spraying, $J$. Therm. Spray Technol., 1993, 2(1), p 79-91

5. O. Rojas, M. Prudent, M.E. López, F. Vargas, and H. Ageorges, Influence of Atmospheric Plasma Spraying Parameters on Porosity Formation in Coatings Manufactured from 45S5 Bioglass ${ }^{\circledR}$ powder, J. Therm. Spray Technol., 2020, 29, p 185-198

6. S. Semenov and B. Cetegen, Spectroscopic Temperature Measurements in Direct Current Arc Plasma Jets used in Thermal Spray Processing of Materials, J. Therm. Spray Technol., 2001, 10, p 326-336

7. K. Bobzin, W. Wietheger, M.A. Knoch, and S.R. Dokhanchi, Estimation of Particle Mass Flow Rate in Free Jet Using In-Flight Particle Diagnostics in Plasma Spraying, J. Therm. Spray Technol., 2020, 29, p 921-931

8. R.S. Lima, B.M.H. Guerreiro, N. Curry, M. Leitner, and K. Körner, Environmental, Economical, and Performance Impacts of Ar- $\mathrm{H}_{2}$ and $\mathrm{N}_{2}-\mathrm{H}_{2}$ Plasma-Sprayed YSZ TBCs, J. Therm. Spray Technol., 2020, 29, p 74-89

9. J.-F. Bisson, C. Moreau, M. Dorfman, C. Dambra, and J. Mallon, Influence of Hydrogen on the Microstructure of Plasma-Sprayed Yttria-Stabilized Zirconia Coatings, J. Therm. Spray Technol., 2005, 14(1), p 85-90

10. E. Nogues, M. Vardelle, P. Fauchais, and P. Granger, Arc Voltage Fluctuations: Comparison Between Two Plasma Torch Types, Surf. Coat. Technol., 2008, 202(18), p 4387-4393

11. S. Ghorui, M. Vysohlid, J.V.R. Heberlein, and E. Pfender, Probing Instabilities in Arc Plasma Devices Using Binary Gas Mixtures, Phys. Rev. E, 2007, https://doi.org/10.1103/physreve. 76.016404

12. G. Mauer, Effect of Hydrogen Admixture on Plasma Jet Characteristics in Low Pressure Spray Processes, International Thermal Spray Conference and Exposition (ITSC 2019): New Waves of Thermal Spray Technology for Sustainable Growth, F. Azarmi, Y. Lau, J. Veilleux, C. Widener, F. Toma, H. Koivuluoto, K. Balani, H. Li, K. Shinoda, Ed., May 26-29, 2019 (Yokohama, Japan), Oerlikon Metco, Saint-Gobain, Salloytech, ASM International, 2019, pp. 650-659

13. P. Fauchais, J. Heberlein and M. Boulos, Thermal Spray Fundamentals, From powder to part, 1st ed., Springer, ISBN 978-0387-28319-7, 2014

14. R.C. Seshadri and S. Sampath, Characteristics of Conventional and Cascaded Arc Plasma Spray-Deposited Ceramic Under Standard and High-Throughput Conditions, J. Therm. Spray Technol., 2019, 28(4), p 690-705

15. A. Vardelle, C. Moreau, J. Akedo, H. Ashrafizadeh, C.C. Berndt, J.O. Berghaus, M. Boulos, J. Brogan, A.C. Bourtsalas, A. Dolatabadi, M. Dorfman, T.J. Eden, P. Fauchais, G. Fisher, F. Gaertner, M. Gindrat, R. Henne, M. Hyland, E. Irissou, E.H. Jordan, K.A. Khor, A. Killinger, Y.-C. Lau, C.-J. Li, L. Li, J. Longtin, N. Markocsan, P.J. Masset, J. Matejicek, G. Mauer, A. McDonald, J. Mostaghimi, S. Sampath, G. Schiller, K. Shinoda, M.F. Smith, A.A. Syed, N.J. Themelis, F.-L. Toma, J.P. Trelles,
R. Vassen, and P. Vuorist, The 2016 Thermal Spray Roadmap, $J$. Therm. Spray Technol., 2016, 25(8), p 1376-1440

16. P. Fauchais, M. Vardelle, A. Vardelle, and S. Goutier, What Do We Know, What are the Current Limitations of Suspension Plasma Spraying?, J. Therm. Spray Technol., 2015, 24(7), p $1120-1129$

17. A. Bacciochini, G. Montavon, J. Ilavsky, A. Denoirjean, and P. Fauchais, Porous Architecture of SPS Thick YSZ Coatings Structured at the Nanometer Scale $(\sim 50 \mathrm{~nm})$, J. Therm. Spray Technol., 2010, 19(1-2), p 198-206

18. O. Aranke, M. Gupta, N. Markocsan, X.-H. Li, and B. Kjellman, Microstructural Evolution and Sintering of Suspension PlasmaSprayed Columnar Thermal Barrier Coatings, J. Therm. Spray Technol., 2019, 28, p 198-211

19. O. Tingaud, P. Bertrand, and G. Bertrand, Microstructure and Tribological Behavior of Suspension Plasma Sprayed $\mathrm{Al}_{2} \mathrm{O}_{3}$ and $\mathrm{Al}_{2} \mathrm{O}_{3}$-YSZ Composite Coatings, Surf. Coat. Technol., 2010, 205(4), p 1004-1008

20. A. Guignard, G. Mauer, R. Vaßen, and D. Stöver, Deposition and Characteristics of Submicrometer-Structured Thermal Barrier Coatings by Suspension Plasma Spraying, J. Therm. Spray Technol., 2012, 21(3-4), p 416-424

21. B. Bernard, A. Quet, L. Bianchi, A. Joulia, A. Malié, V. Schick, and B. Rémy, Thermal Insulation Properties of YSZ Coatings: Suspension Plasma Spraying (SPS) Versus Electron Beam Physical Vapor Deposition (EB-PVD) and Atmospheric Plasma Spraying (APS), Surf. Coat. Technol., 2017, 318, p 122-128

22. Y. Zhao, Y. Wang, Z. Yu, M.-P. Planche, F. Peyraut, H. Liao, A. Lasalle, A. Allimant, and G. Montavon, Microstructural, Mechanical and Tribological Properties of Suspension Plasma Sprayed YSZ/h-BN Composite Coating, J. Eur. Ceram. Soc., 2018, 38(13), p 4512-4522

23. R.S. Lima, B.M.H. Guerreiro, and M. Aghasibeig, Microstructural Characterization and Room-Temperature Erosion Behavior of As-Deposited SPS, EB-PVD and APS YSZ-Based TBCs, $J$. Therm. Spray Technol., 2019, 28, p 223-232

24. S. Mahade, C. Ruelle, N. Curry, J. Holmberg, S. Björklund, N. Markocsan, and P. Nylén, Understanding the Effect of Material Composition and Microstructural Design on the Erosion Behavior of Plasma Sprayed Thermal Barrier Coatings, Appl. Surf. Sci., 2019, 488, p 170-184

25. N. Curry, K. VanEvery, T. Snyder, J. Susnjar, and S. Bjorklund, Performance Testing of Suspension Plasma Sprayed Thermal Barrier Coatings Produced with Varied Suspension Parameters, Coatings, 2015, 5(3), p 338-356

26. N. Curry, Z. Tang, N. Markocsan, and P. Nylén, Influence of Bond Coat Surface Roughness on the Structure of Axial Suspension Plasma Spray Thermal Barrier Coatings-Thermal and Lifetime Performance, Surf. Coat. Technol., 2015, 268, p 15-23

27. B. Bernard, L. Bianchi, A. Malié, A. Joulia, and B. Rémy, Columnar Suspension Plasma Sprayed Coating Microstructural Control for Thermal Barrier Coating Application, J. Eur. Ceram. Soc., 2016, 36(4), p 1081-1089

28. X. Chen, S. Kuroda, T. Ohnuki, H. Araki, M. Watanabe, and Y. Sakka, Effects of Processing Parameters on the Deposition of Yttria Partially Stabilized Zirconia Coating During Suspension Plasma Spray, J. Am. Ceram. Soc., 2016, 99(11), p 3546-3555

29. R.C. Seshadri, G. Dwivedi, V. Viswanathan, and S. Sampath, Characterizing Suspension Plasma Spray Coating Formation Dynamics through Curvature Measurements, J. Therm. Spray Technol., 2016, 25(8), p 1666-1683

30. D. Zhou, O. Guillon, and R. Vaßen, Development of YSZ Thermal Barrier Coatings Using Axial Suspension Plasma Spraying, Coatings, 2017, 7(8), p 120-137

31. A. Ganvir, R.F. Calinas, N. Markocsan, N. Curry, and S. Joshi, Experimental Visualization of Microstructure Evolution During 
Suspension Plasma Spraying of Thermal Barrier Coatings, J. Eur. Ceram. Soc., 2019, 39(2-3), p 470-481

32. R. Etchart-Salas, V. Rat, J.-F. Coudert, P. Fauchais, N. Caron, K. Wittman, and S. Alexandre, Influence of Plasma Instabilities in Ceramic Suspension Plasma Spraying, J. Therm. Spray Technol., 2007, 16(5-6), p 857-865

33. A. Joulia, W. Duarte, S. Goutier, M. Vardelle, A. Vardelle, and S. Rossignol, Tailoring the Spray Conditions for Suspension Plasma Spraying, J. Therm. Spray Technol., 2015, 24, p 24-29

34. J. Fazilleau, Contribution à la compréhension des phénomènes impliqués dans la réalisation de dépôts finement structurés d'oxydes par par projection de suspensions par plasma (Contribution to the understanding of the phenomena implied in the achievement of finely structured oxides coatings by D. C. suspension plasma spraying), Ph.D. Thesis, University of Limoges, 1999 (in French)
35. M.-P. Planche, J.-F. Coudert, and P. Fauchais, Velocity Measurements for Arc Jets Produced by a D.C. Plasma Spray Torch, Plasma Chem. Plasma Process., 1998, 18(2), p 263-286

36. B. Patheyron and G. Delluc, software TTWinner, 2003, http:// ttwinner.free.fr/

37. S. Bansard, Etude de l'ablation d'un composite -fibres de carbone, résine phénolique-par impact de gouttes d'alumine: Conception d'un banc d'expériences (Study of the ablation of a carbon/phenolic composite under the impact of alumina drops: experimental bench conception), Ph.D. Thesis, University of Limoges, 2004 (in French)

Publisher's Note Springer Nature remains neutral with regard to jurisdictional claims in published maps and institutional affiliations. 